\title{
Characteristics and Performance of Nanozinc Oxide/Mesoporous Silica Gel Photocatalytic Composite Prepared by a Sol-Gel Method
}

\author{
Hang Xu, Tianlong Yu, and Yi Liu \\ Chemical Engineering and Pharmaceutics School, Henan University of Science and Technology, Luoyang 471023, China \\ Correspondence should be addressed to Hang Xu; xhinbj@126.com
}

Received 5 January 2015; Accepted 23 February 2015

Academic Editor: Antonios Kelarakis

Copyright (C) 2015 Hang Xu et al. This is an open access article distributed under the Creative Commons Attribution License, which permits unrestricted use, distribution, and reproduction in any medium, provided the original work is properly cited.

Nano-ZnO loaded mesoporous $\mathrm{SiO}_{2}$ was prepared by sol-gel technology as a photocatalytic composite. XRD, SEM, TEM, EDX, and $\mathrm{N}_{2}$ sorption isotherms were used to characterize the nano- $\mathrm{ZnO} /$ mesoporous $\mathrm{SiO}_{2}$. Acid Red 18 was used as simulated pollutant to determine the photocatalytic performance of nano- $\mathrm{ZnO} /$ mesoporous $\mathrm{SiO}_{2}$ under ultraviolet light and solar light. The results showed that $6.4 \mathrm{~nm} \mathrm{ZnO}$ was obtained and immobilized on mesoporous $\mathrm{SiO}_{2}$. Compared to the mesoporous $\mathrm{SiO}_{2}$, the surface area and average pore width of nano- $\mathrm{ZnO} /$ mesoporous $\mathrm{SiO}_{2}$ were reduced by $12 \mathrm{~m}^{2} / \mathrm{g}$ and $0.7 \mathrm{~nm}$, respectively. $50 \% \mathrm{ZnO}$ content in a composite calcinated at $200^{\circ} \mathrm{C}$ exhibited the best photocatalytic activity. The removal of Acid Red 18 under solar irradiation was $10 \%$ higher than ultraviolet light.

\section{Introduction}

Zinc oxide $(\mathrm{ZnO})$ is an important $n$-type semiconductor with a wide-bandgap energy of $3.37 \mathrm{eV}$ [1] and an exciton binding energy of $60 \mathrm{meV}$ at room temperature. $\mathrm{ZnO}$ is suitable as a photocatalyst for decomposing organic contamination in aqueous solutions and can present a higher photocatalytic activity than $\mathrm{TiO}_{2}[2,3]$. Compared with bulk $\mathrm{ZnO}$, nanopowder $\mathrm{ZnO}$ improves the catalytic activity due to the quantum size effect [4]. Su et al. prepared quantumsized $\mathrm{ZnO}$ for photocatalytic degradation of the reactive dye "brilliant blue X-BR" with nearly $100 \%$ color removal [5]. In a subsequent study, nano- $\mathrm{ZnO}$ under UV irradiation exhibited about 100\% removal of "Acid Yellow 23" within 60 min [6].

However, nano- $\mathrm{ZnO}$ is so small that it is difficult to recycle from aqueous solutions following photocatalytic processes, which limits its application in water treatment. To overcome this shortcoming, Motshekga et al. developed a composite photocatalyst on which nano- $\mathrm{ZnO}$ was immobilized on larger particle carriers [7]. Mesoporous $\mathrm{SiO}_{2}$ is an excellent carrier for catalysis $[8,9]$ because it provides an increased catalytic space over microporous carriers, which is advantageous for adsorption of molecular dye. Mesoporous
$\mathrm{SiO}_{2}$ could decrease the dosage of the nano- $\mathrm{ZnO}$ and increase the utilization rate. On the other hand, mesoporous $\mathrm{SiO}_{2}$ could improve the dispersion of nano- $\mathrm{ZnO}$ and reduce the reunion.

In this study, a photocatalytic composite of nano- $\mathrm{ZnO}$ immobilized on mesoporous $\mathrm{SiO}_{2}$ was prepared by a sol-gel method. X-ray diffraction, $\mathrm{N}_{2}$ sorption isotherms, scanning electron microscopy, transmission electron microscopy, and energy-dispersive spectroscopy were used to comprehensively characterize the nano- $\mathrm{ZnO} /$ mesoporous $\mathrm{SiO}_{2}$ composite. Acid Red 18 was used as a simulated pollutant to determine the photocatalytic performance of our composite under ultraviolet or solar light.

\section{Experimental}

2.1. Preparation of Nano-ZnO/Mesoporous $\mathrm{SiO}_{2}$ Composite. To prepare the nano- $\mathrm{ZnO} /$ mesoporous $\mathrm{SiO}_{2}$ composite, $1.10 \mathrm{~g}$ zinc acetate was dissolved with stirring in $50 \mathrm{~mL}$ anhydrous ethanol at $80^{\circ} \mathrm{C}$. A certain quantity of mesoporous silica gel was added to the zinc acetate solution to form a hybrid system. A lithium hydroxide solution of $0.29 \mathrm{~g}$ lithium hydroxide and $50 \mathrm{~mL}$ anhydrous ethanol was added with $100 \mathrm{~mL}$ 


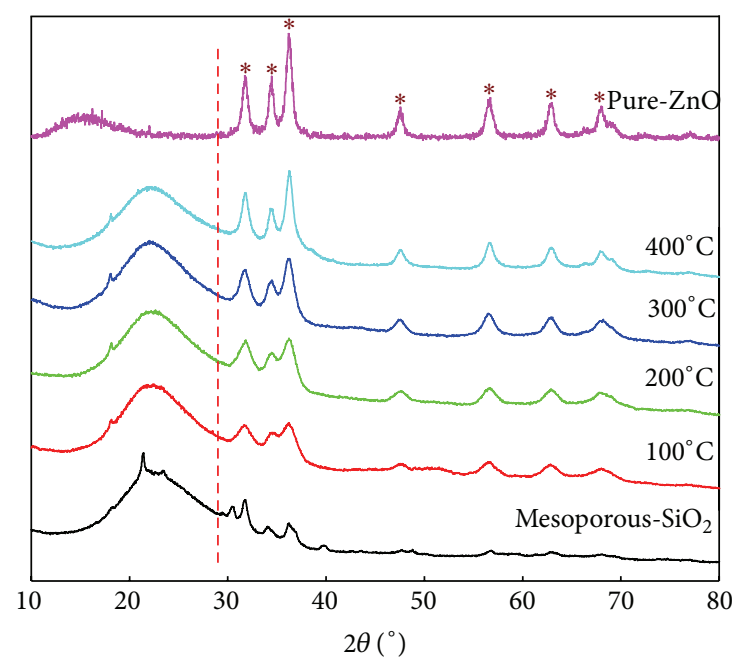

FIgURE 1: $\mathrm{XRD}$ of $\mathrm{ZnO}, \mathrm{SiO}_{2}$, and $\mathrm{ZnO} / \mathrm{SiO}_{2}$ from different calcination temperatures.

$n$-hexane at room temperature to the hybrid system. A white gel was obtained by overnight refrigeration, from which a solid was obtained by centrifugation and drying at $100^{\circ} \mathrm{C}$. The nano- $\mathrm{ZnO} /$ mesoporous $\mathrm{SiO}_{2}$ composite was prepared by calcination at 200 to $400^{\circ} \mathrm{C}$ over $2 \mathrm{~h}$.

2.2. Characterization of Materials. The crystal phases of nano- $\mathrm{ZnO} /$ mesoporous $\mathrm{SiO}_{2}$ were analyzed by X-ray diffraction (XRD) on a PaNalytical X-ray diffractometer (X'Pert Pro MPD, Netherlands) using $\mathrm{Cu} \mathrm{K} \alpha$ radiation. Scanning electron microscopy (SEM) was performed by a Nova NanoSEM (FEI, USA) with energy-dispersive X-ray spectroscopy (EDX). Transmission electron microscope (TEM) was carried out using a JEM-2010 (JEOL, Japan). $\mathrm{N}_{2}$ sorption isotherms were measured using a Micromeritics ASAP2020 system (USA).

2.3. Photocatalytic Experiment. Acid Red 18 was used to determine photocatalytic performance. The maximum absorption wavelength of Acid Red 18 was $506 \mathrm{~nm}$. To assess photocatalytic activity, $200 \mathrm{~mL}$ of $20 \mathrm{mg} / \mathrm{L}$ Acid Red 18 and a certain dosage of nano- $\mathrm{ZnO} /$ mesoporous $\mathrm{SiO}_{2}$ were added to a $250 \mathrm{~mL}$ beaker with magnetic stirring. A $10 \mathrm{~cm}$ long mercury UV lamp (10 W Guangdong Bright Star) was used as the radiation source with a wavelength of $245 \mathrm{~nm}$. The solar light experiment was carried out under sunlight irradiation. After a certain reaction interval of $40 \mathrm{~min}$, a $10 \mathrm{~mL}$ sample was removed and centrifuged at $12000 \mathrm{rpm}$ to remove the catalyst. The dyestuff absorbance of Acid Red 18 was analyzed by a UV-2102PC UV-Vis spectrophotometer (UNICO, China) after centrifuging. The degradation rate of Acid Red 18 was calculated by the following equation:

$$
\text { Removal }=\frac{\left(C_{0}-C_{t}\right)}{C_{0}} \times 100 \% .
$$

Here, $C_{0}$ was the initial concentration of Acid Red 18 and $C_{t}$ was the concentration of Acid Red 18 at $t$ time.

\section{Results and Discussion}

3.1. XRD Analysis. Figure 1 shows $\mathrm{XRD}$ analysis of $\mathrm{ZnO}$, mesoporous $\mathrm{SiO}_{2}$, and nano- $\mathrm{ZnO} /$ mesoporous $\mathrm{SiO}_{2}$ composites at different calcination temperature from $100^{\circ} \mathrm{C}$ to $400^{\circ} \mathrm{C}$. XRD of mesoporous $\mathrm{SiO}_{2}$ yields an intense peak from 20 to $30^{\circ}$ [10]. The large band (not a peak) between $20^{\circ}$ and $30^{\circ}$ is easily ascribed to amorphous silica. The $\mathrm{ZnO}$ characteristic peaks are shown at $2 \theta$ values of $31.7,34.4,36.2$, $47.5,56.5,62.8,67.9$, and $68.8^{\circ}$ in Figure 1 . All peaks can be well indexed to standard patterns (JCPDS 36-1451) without any impurity phases [11]. The major peaks of $\mathrm{ZnO}$ at $2 \theta$ values of $31.7,34.4,36.2$, and $47.5^{\circ}$ can be indexed to (100), (002), (101), and (102) crystal planes and characteristic $\mathrm{ZnO}$ peaks become obvious at calcination temperatures above $200^{\circ} \mathrm{C}$. From Figure 1, it can be seen clearly that the half peak widths of characteristic peaks gradually reduce with increasing calcination temperatures. This indicates that $\mathrm{ZnO}$ particle sizes increase with calcination temperature. According to the Scherrer equation [12], the $\mathrm{ZnO}$ particle size of composite was $6.4 \mathrm{~nm}$. Furthermore, the crystalline peaks suggest that the sample measured is already zinc precursor impregnated silica and not pure silica.

3.2. $\mathrm{N}_{2}$ Sorption Analysis. Figure 2 shows that both nano$\mathrm{ZnO} /$ mesoporous $\mathrm{SiO}_{2}$ and mesoporous $\mathrm{SiO}_{2}$ exhibit type IV isotherms [13] with high surface areas (318 and $330 \mathrm{~m}^{2} / \mathrm{g}$ ) and average pore widths (7.9 and $8.6 \mathrm{~nm}$ ), respectively. Thus, compared with mesoporous $\mathrm{SiO}_{2}$, the surface area and average pore width of the composite fell by $12 \mathrm{~m}^{2} / \mathrm{g}$ and $0.7 \mathrm{~nm}$, respectively. This suggests that nano- $\mathrm{ZnO}$ is confined inside the pores of mesoporous $\mathrm{SiO}_{2}$.

3.3. Morphological Analysis. The SEM of nano-ZnO/mesoporous $\mathrm{SiO}_{2}$ (Figure 3(a)) shows a large particle size, which is advantageous for catalyst recovery from aqueous solutions. From the EDX analysis of the composite, the atomic ratio of $\mathrm{Zn}$ to $\mathrm{Si}$ is about 3:4. Thus, the mass content of $\mathrm{ZnO}$ 

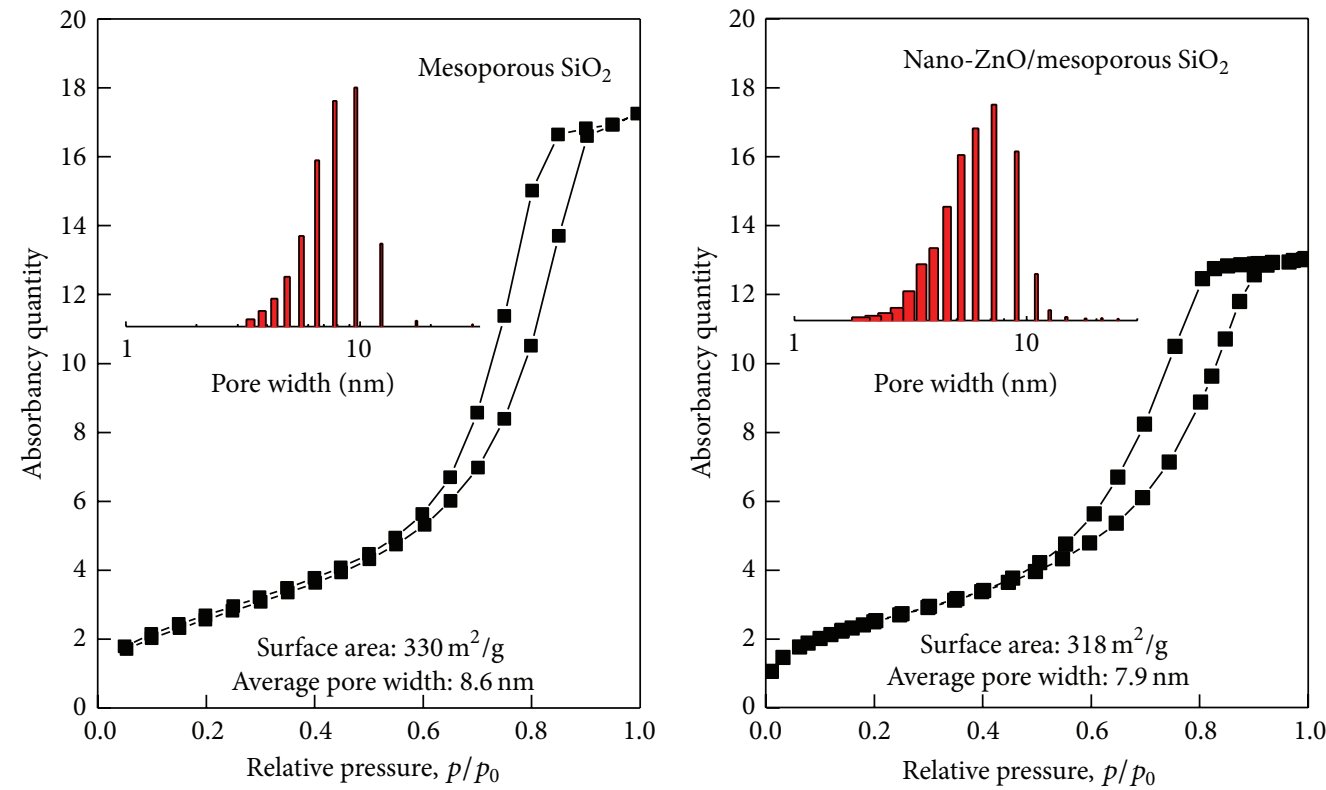

FIGURE 2: Comparison of nitrogen isotherm data showing pore size distribution for $\mathrm{SiO}_{2}$ and $\mathrm{ZnO} / \mathrm{SiO}_{2}$.

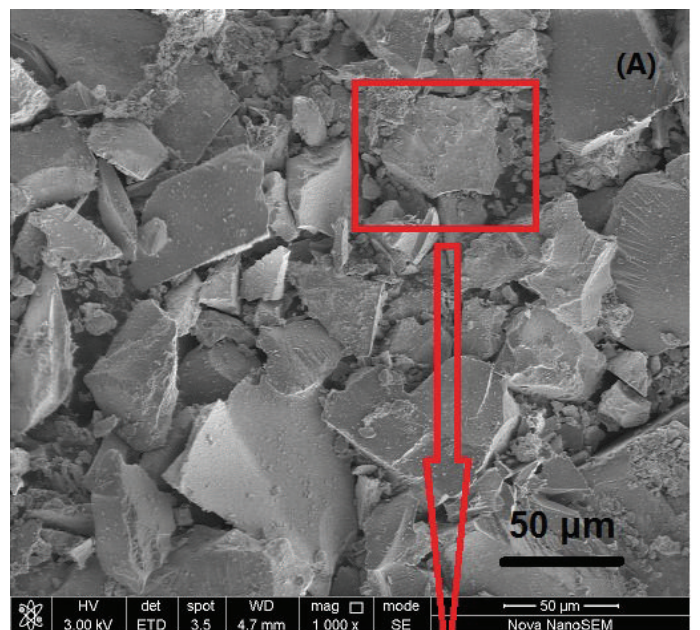

(a)

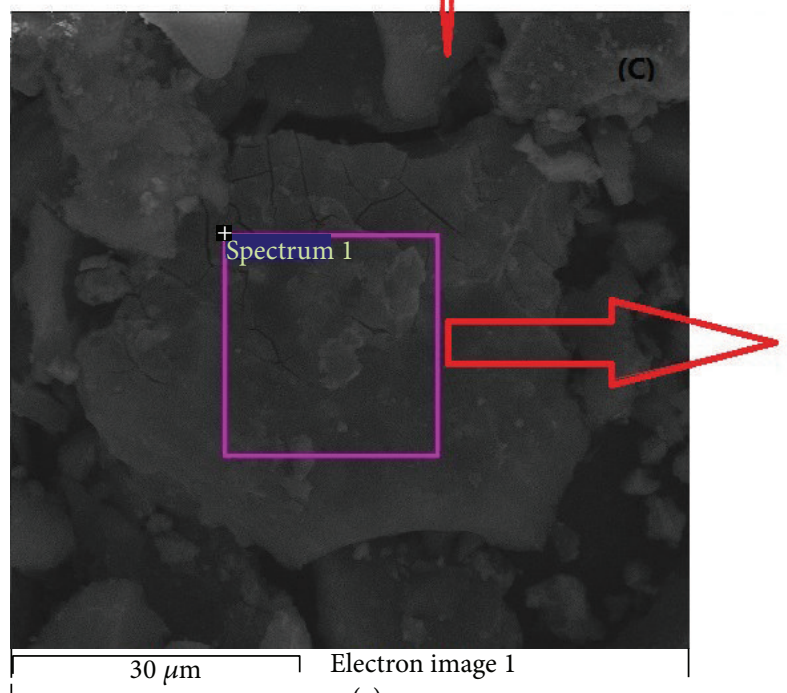

(c)

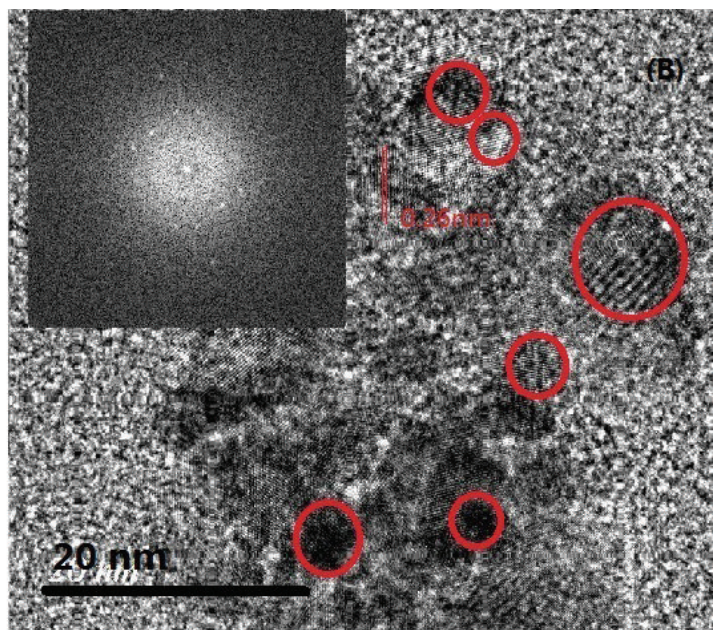

(b)

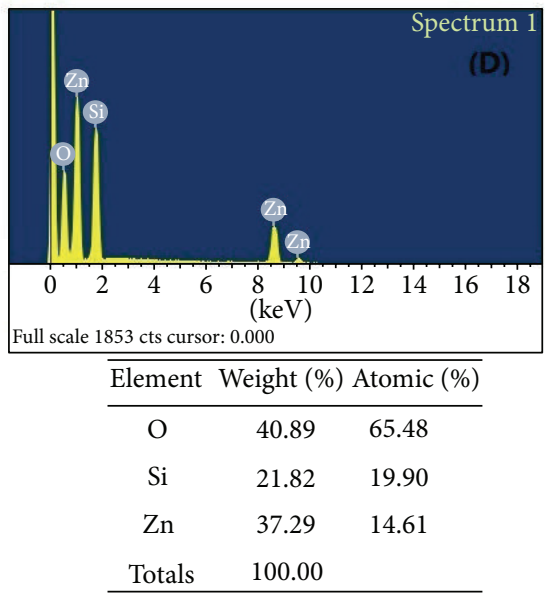

(d)

Figure 3: SEM, TEM, and EDX of nano- $\mathrm{ZnO} /$ mesoporous $\mathrm{SiO}_{2}(50 \% \mathrm{ZnO})$. 


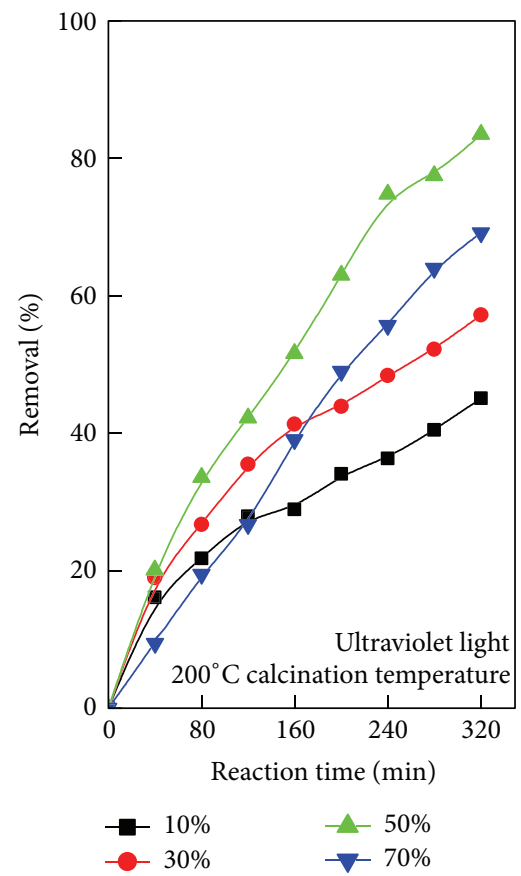

(a)

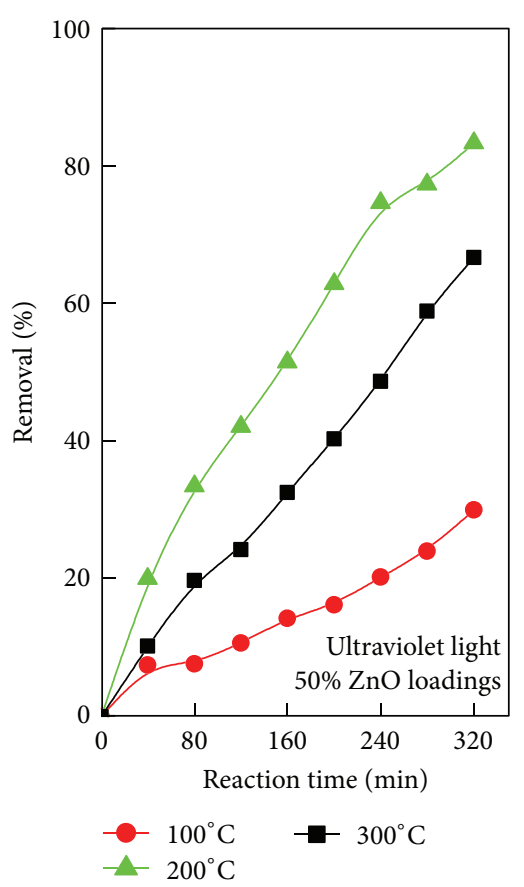

(b)

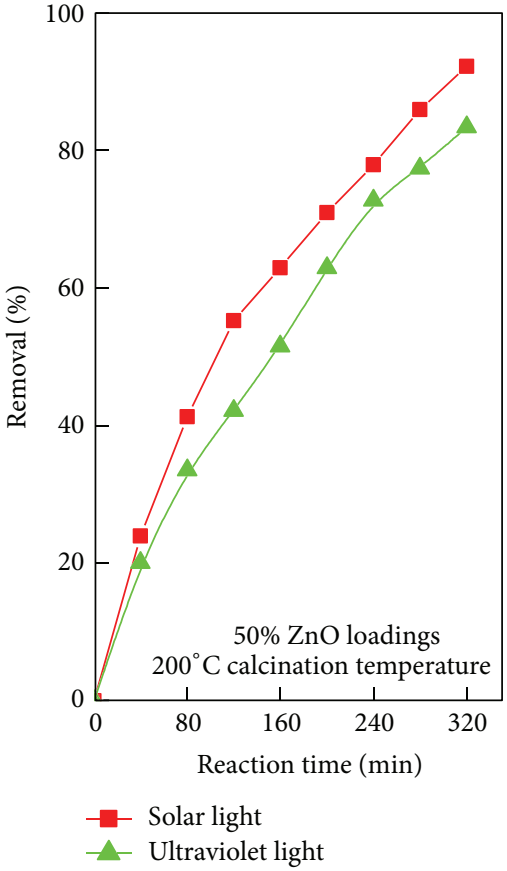

(c)

Figure 4: Photocatalytic performance of nano-ZnO/mesoporous $\mathrm{SiO}_{2}$ ((a) $\mathrm{ZnO}$ loadings effect; (b) calcination temperature effect; (c) light source effect).

in the composite is about $57 \%$, close to the theoretical $50 \%$ $\mathrm{ZnO}$ content. From TEM of the composite (Figure 3(b)), the $\mathrm{ZnO}$ particle sizes are shown to be on the nanoscale, which is similar to the results of the XRD analysis. Combined with SAED, the TEM image shows sharp lattice fringes with $0.26 \mathrm{~nm}$ spacing in the nano- $\mathrm{ZnO} /$ mesoporous $\mathrm{SiO}_{2}$, corresponding to the (002) planes of wurtzite phase $\mathrm{ZnO}$ crystals.

3.4. Photocatalytic Activity Test of Composite. Figure 4(a) shows the photocatalytic performance of nano- $\mathrm{ZnO} / \mathrm{mes}$ oporous $\mathrm{SiO}_{2}$ composites with various $\mathrm{ZnO}$ contents from $10 \%$ to $70 \%$. The composite with $50 \% \mathrm{ZnO}$ content showed the best photocatalytic activity with $83.5 \%$ removal of Acid Red 18 at $320 \mathrm{~min}$. Excessive $\mathrm{ZnO}$ in the composite may cause aggregation to yield increased particle sizes, which can reduce the quantum size effect. Mesoporous $\mathrm{SiO}_{2}$ has a great adsorption amount of Acid Red 18. The high $\mathrm{ZnO}$ content means the low $\mathrm{SiO}_{2}$ in composite photocatalyst.

The decline of adsorption ability is also causing the decrease of catalytic activity. Under UV irradiation, electronic $\left(\mathrm{e}^{-}\right)$can be agitated from valence band $(\mathrm{VB})$ to conduction band (CB) of $\mathrm{ZnO}$ to produce hole $\left(\mathrm{h}^{+}\right)$. The hole can react with hydroxyl ion to generate hydroxyl radical $(\bullet \mathrm{OH})$. The $\bullet \mathrm{OH}$ shows a strong oxidation ability to decompose the organic contamination in aqueous. The number of $\bullet \mathrm{OH}$ can be increased with the rise of nano- $\mathrm{ZnO}$ content in nano$\mathrm{ZnO} /$ mesoporous $\mathrm{SiO}_{2}$. However, excessive $\mathrm{ZnO}$ in composite photocatalyst may aggregate together to increase nano$\mathrm{ZnO}$ particle size. The big particle size of $\mathrm{ZnO}$ can reduce the quantum size effect and decrease the catalytic activity.
On the other hand, mesoporous $\mathrm{SiO}_{2}$ has a good ability of adsorption of organic contaminants. The high $\mathrm{ZnO}$ content means the low mesoporous $\mathrm{SiO}_{2}$ in composite photocatalyst. The decline of adsorption ability of $\mathrm{ZnO} /$ mesoporous $\mathrm{SiO}_{2}$ is also causing the decrease of catalytic activity. So, the $50 \%$ $\mathrm{ZnO}$ content in $\mathrm{ZnO} /$ mesoporous $\mathrm{SiO}_{2}$ composite is optimal value in this study.

The precursor obtained after sol-gel procedure was treated by calcination. The nano- $\mathrm{ZnO} /$ mesoporous $\mathrm{SiO}_{2}$ composites were prepared at different calcination temperatures at $100^{\circ} \mathrm{C}, 200^{\circ} \mathrm{C}$, and $300^{\circ} \mathrm{C}$. The catalytic activity of nano- $\mathrm{ZnO} /$ mesoporous $\mathrm{SiO}_{2}$ composite is shown in Figure 4(b). From Figure 4(b), it is shown clearly that the high photocatalytic activity of nano- $\mathrm{ZnO} /$ mesoporous $\mathrm{SiO}_{2}$ composites is calcinated at $200^{\circ} \mathrm{C}$. Higher calcination temperature can cause particle aggregation and result in a decrease in photocatalytic activity.

Finally Figure 4(c) shows that the degradation of Acid Red 18 under solar irradiation was $10 \%$ higher than under ultraviolet irradiation. This is because sunlight contains a mixed spectrum and nano- $\mathrm{ZnO} /$ mesoporous $\mathrm{SiO}_{2}$ composites can use wider ranges of light, leading to $93 \%$ degradation under solar light irradiation.

\section{Conclusions}

A photocatalytic composite of nano- $\mathrm{ZnO}$ immobilized on mesoporous $\mathrm{SiO}_{2}$ was prepared using a sol-gel process. $6.4 \mathrm{~nm} \mathrm{ZnO}$ was obtained and immobilized on mesoporous $\mathrm{SiO}_{2}$. Compared to mesoporous $\mathrm{SiO}_{2}$, the surface area and average pore width of nano- $\mathrm{ZnO} /$ mesoporous $\mathrm{SiO}_{2}$ 
decreased by $12 \mathrm{~m}^{2} / \mathrm{g}$ and $0.7 \mathrm{~nm}$, respectively. Composites with a $\mathrm{ZnO}$ composition of $50 \%$ prepared at $200^{\circ} \mathrm{C}$ calcination temperature had the best photocatalytic activity, achieving 95\% color removal at 320 min under solar light. The removal of Acid Red 18 under solar irradiation was 10\% higher than under ultraviolet light.

\section{Conflict of Interests}

The authors declare that they have no conflict of interests.

\section{Acknowledgments}

This work is supported by the National Nature Science Foundations of China (no. 21006057) and Henan Provincial Science and Technology Foundation (no. 142102210427).

\section{References}

[1] K. Sowri Babu, A. Ramachandra Reddy, C. Sujatha, and K. Venugopal Reddy, "Effects of precursor, temperature, surface area and excitation wavelength on photoluminescence of $\mathrm{ZnO} /$ mesoporous silica nanocomposite," Ceramics International, vol. 39, no. 3, pp. 3055-3064, 2013.

[2] M. A. Behnajady, N. Modirshahla, and R. Hamzavi, "Kinetic study on photocatalytic degradation of C.I. Acid Yellow 23 by ZnO photocatalyst," Journal of Hazardous Materials, vol. 133, no. 1-3, pp. 226-232, 2006.

[3] I. Fatimah, S. Wang, and D. Wulandari, " $\mathrm{ZnO} / \mathrm{montmorillonite}$ for photocatalytic and photochemical degradation of methylene blue," Applied Clay Science, vol. 53, no. 4, pp. 553-560, 2011.

[4] R. Hong, T. Pan, J. Qian, and H. Li, "Synthesis and surface modification of $\mathrm{ZnO}$ nanoparticles," Chemical Engineering Journal, vol. 119, no. 2-3, pp. 71-81, 2006.

[5] S. Su, S. X. Lu, and W. G. Xu, "Photocatalytic degradation of reactive brilliant blue $X-B R$ in aqueous solution using quantumsized ZnO," Materials Research Bulletin, vol. 43, no. 8-9, pp. 2172-2178, 2008.

[6] N. Modirshahla, A. Hassani, M. A. Behnajady, and R. Rahbarfam, "Effect of operational parameters on decolorization of Acid Yellow 23 from wastewater by UV irradiation using $\mathrm{ZnO}$ and $\mathrm{ZnO} / \mathrm{SnO}_{2}$ photocatalysts," Desalination, vol. 271, no. 1-3, pp. 187-192, 2011.

[7] S. C. Motshekga, S. S. Ray, M. S. Onyango, and M. N. B. Momba, "Microwave-assisted synthesis, characterization and antibacterial activity of $\mathrm{Ag} / \mathrm{ZnO}$ nanoparticles supported bentonite clay," Journal of Hazardous Materials, vol. 262, no. 5, pp. 439-446, 2013.

[8] C. Cannas, M. Mainas, A. Musinu, and G. Piccaluga, " $\mathrm{ZnO} / \mathrm{SiO}_{2}$ nanocomposites obtained by impregnation of mesoporous silica," Composites Science and Technology, vol. 63, no. 8, pp. 11871191, 2003.

[9] L.-Y. Lin and H. Bai, "Salt-templated synthesis of Ce/Al catalysts supported on mesoporous silica for acetone oxidation," Applied Catalysis B: Environmental, vol. 148-149, pp. 366-376, 2014.

[10] B. Jeong, D. H. Kim, E. J. Park et al., "ZnO shell on mesoporous silica by atomic layer deposition: removal of organic dye in water by an adsorbent and its photocatalytic regeneration," Applied Surface Science, vol. 307, pp. 468-474, 2014.

[11] H. Xu, T. L. Yu, and J. F. Liu, "Photo-degradation of Acid Yellow 11 in aqueous on nano- $\mathrm{ZnO} /$ Bentonite under ultraviolet and visible light irradiation," Materials Letters, vol. 117, no. 3, pp. 263-265, 2014.

[12] W. G. Xu, S. F. Liu, S. X. Lu, S. Y. Kang, Y. Zhou, and H. F. Zhang, "Photocatalytic degradation in aqueous solution using quantum-sized $\mathrm{ZnO}$ particles supported on sepiolite," Journal of Colloid and Interface Science, vol. 351, no. 1, pp. 210-216, 2010.

[13] Q. Tang, H. Xu, Y. Y. Zheng, J. F. Wang, H. S. Li, and J. Zhang, "Catalytic dehydration of methanol to dimethyl ether over micro-mesoporous ZSM-5/MCM-41 composite molecular sieves," Applied Catalysis A: General, vol. 413-414, no. 1, pp. 3642, 2012. 

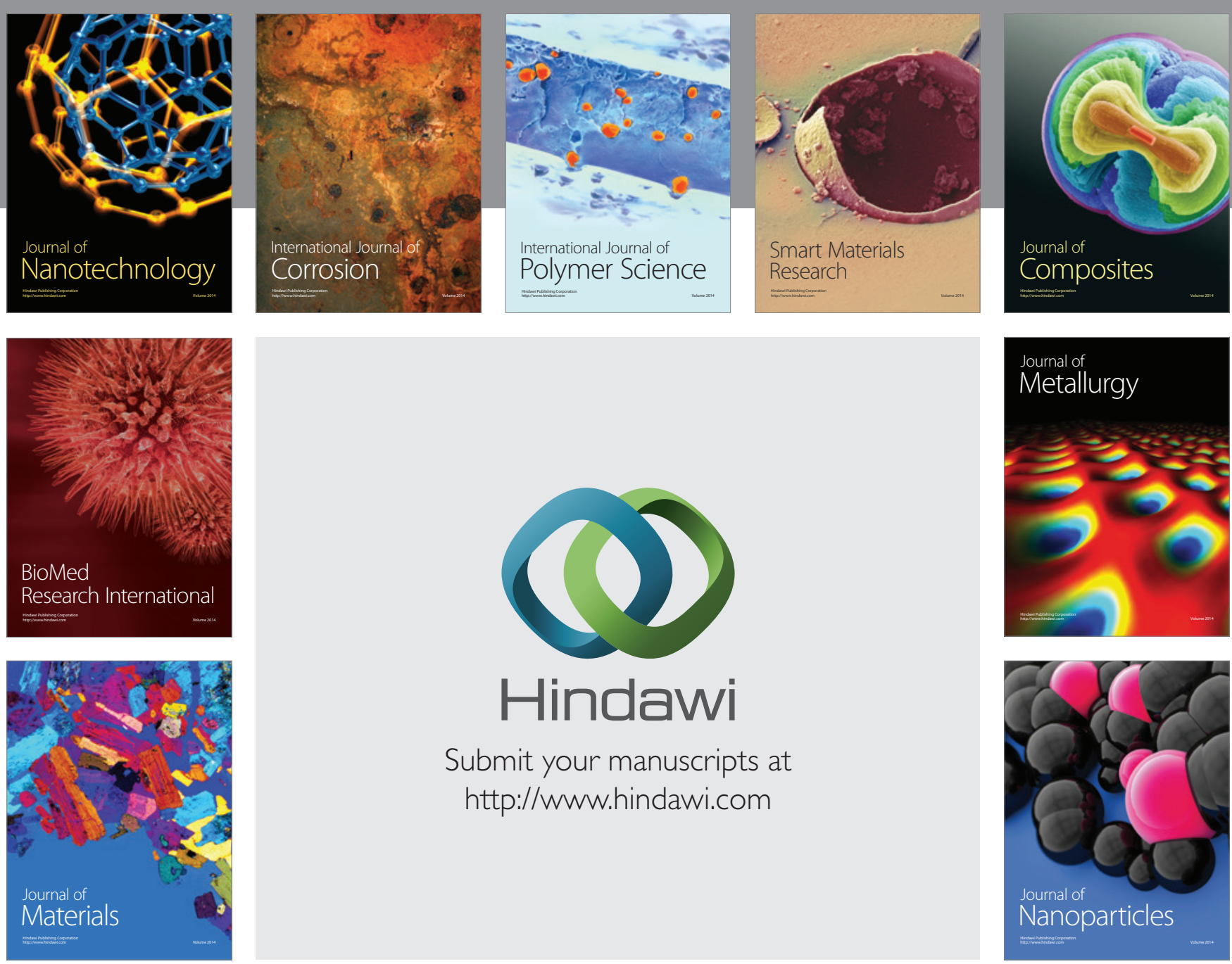

Submit your manuscripts at http://www.hindawi.com
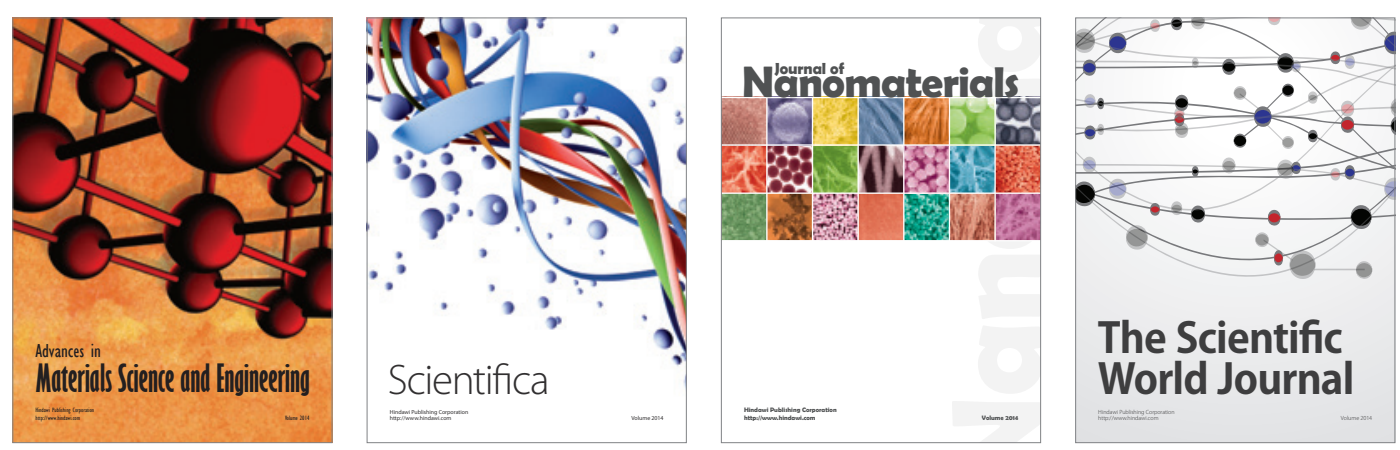

\section{The Scientific World Journal}
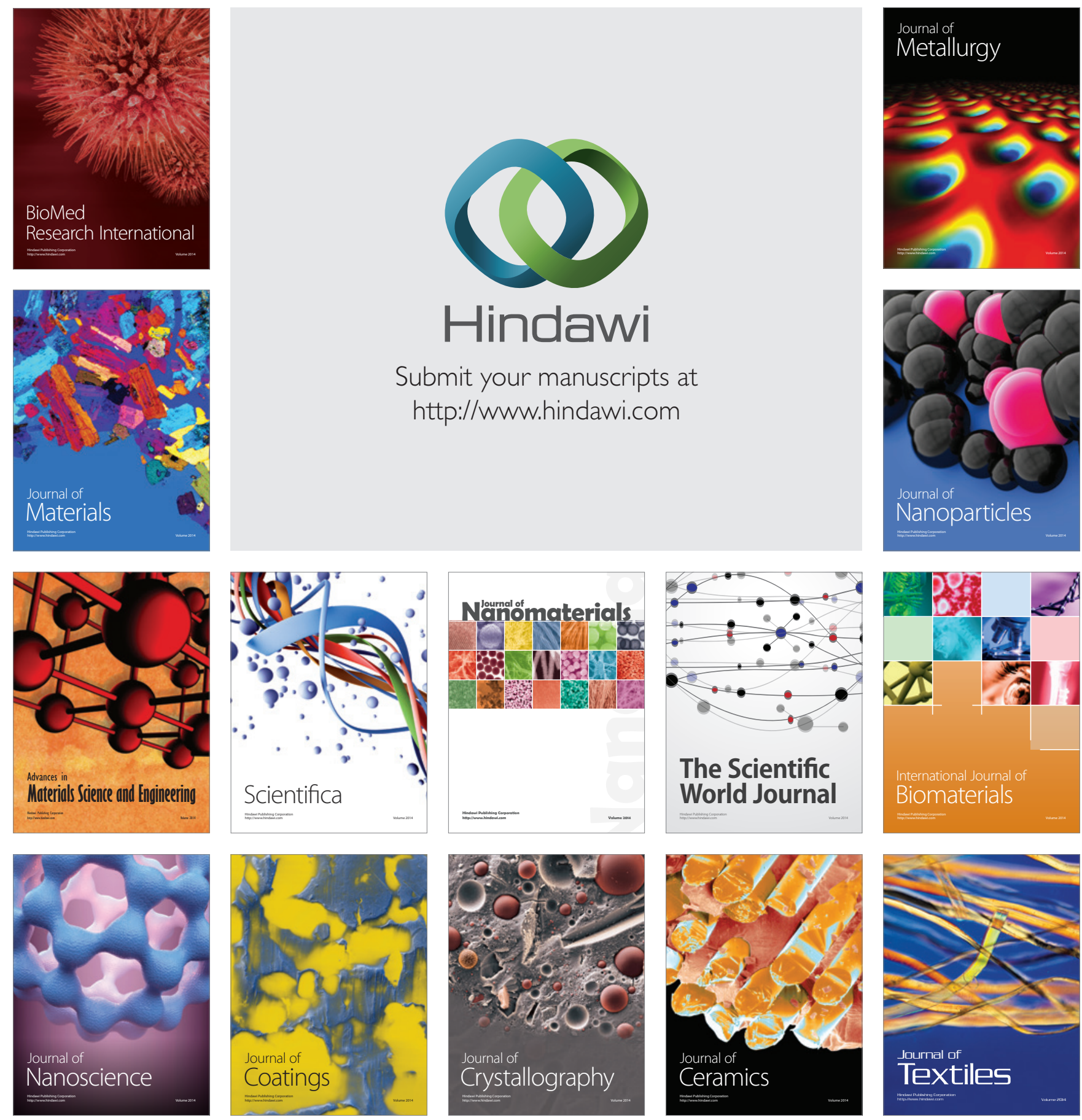